\title{
Open Access in the Czech Republic: an Overview
}

\author{
Ondřej Fabián \\ Tomas Bata University in Zlín, Czech Republic
}

\begin{abstract}
Purpose - the purpose of this article is a complex description and evaluation of open access adoption in the environment of the Czech Republic, from both the green road and golden road point of view.

Design/Methodology/Approach - data and conclusions in this paper are numerically supported by quantitative analyses from several relevant databases (e.g. JCR, Scopus, DOAJ or ROAR).

Findings - the issue of open access has not been given appropriate attention in the Czech Republic. Therefore most of the important activities have only recently been implemented, or they are still underway. Open access is still being completely ignored at the level of Czech state offices and funding agencies, which leads to scientific institutions learning of this phenomenon individually. Compared to other Central European countries, the Czech Republic can be classified as average in certain respects, but it is no competition for developed West European and North American countries in terms of awareness, infrastructure and open access adoption.
\end{abstract}

Originality/Value - this is the very first article that comprehensively sums up all aspects of the issue of open access in the Czech Republic.

Keywords Open Access, Czech Republic, Open Access Journals, Open Repositories

Paper type Research paper

\section{Open Access: a brief introduction}

Open access is a phenomenon that receives an extraordinary amount of attention nowadays as a part of the issue of publishing scientific papers. It poses an alternative to the archetypal publishing model, especially viable in the current situation of dramatic cuts in library budgets. Making scientific materials freely available is becoming ever more interesting not only for users, but even for authors, giving them the opportunity to reach out to a wider target audience. The history of open access starts far in the past (Suber, 2009), however the most dynamic shift comes only after 2000. At that time, a whole series of open access declarations were defined and signed (Harnad et al., 2008) - among the most significant, the Berlin Declaration on Open Access to Knowledge in the Sciences and Humanities[1], Bethesda Statement on Open Access Publishing[2] and the Budapest Open Access Initiative[3]. This particular one defined in very exact terms what is understood under the term of open access:

By "open access" to this literature, we mean its free availability on the public internet, permitting any users to read, download, copy, distribute, print, search, or link to the full texts of these articles, crawl them for indexing, pass them as data to software, or use them for any other lawful purpose, without financial, legal, or technical barriers other than those inseparable from gaining access to the internet itself. The only constraint on reproduction and distribution, and the only role for copyright in this domain, should be to give authors control over the integrity of their work and the right to be properly acknowledged and cited.

The Berlin Declaration then defined two basic approaches to open access - the "golden road", meaning publishing articles in freely available journals and the "green road", meaning free 
accessioning of materials in open repositories (Harnad et al., 2004). Open access gains ground both in terms of institutional and technical support. A number of prominent organizations are beginning to pay more attention to the issue of open access. Many funders are beginning to require the results of funded research to be published in open access mode. Many projects and institutions are arising for support of open access infrastructure and development. Among the projects we can name e.g. DRIVER[4], OpenAIRE[5] or PEER[6], among the institutions COAR[7], Open Archives Initiative[8] or the British JISC[9] organization which is very active in open access support. Also the European Commission is appropriately mindful and co-funds many open access development projects. The raised interest of authors in free distribution of their articles has coerced even commercial publishers to react. They have started offering a so-called hybrid journal model which means that these journals contain both paid and freely available journals and the author who wants his article available in open access mode pays the fees for such publishing (Bird, 2010; WALTHAM, 2005). A network of registries is also forming to keep track of freely available journals (e.g. DOAJ) but also of open repositories (e.g. ROAR, OpenDOAR).

The technical infrastructure is currently available in the form of working repositories, registries, information exchange protocols, software for support of open journals, open repositories etc. These high-quality services thus grant free materials a high visibility which results among other things in an increase in citations. This fact is supported by many independent studies (Swan, 2010). However the precondition for open access publishing is not only technical readiness, but also engagement of governments of individual countries and key scientific institutions to its implementation. And this is where significant differences are obvious, as described in the next chapters of this paper which makes a detailed analysis of open access issue state and development in the Czech Republic.

\section{Literature}

The article contains the basic literature on the open access issue, which was introduced in the previous chapter. In addition, the article makes comparisons with other Central European countries (Poland, Hungary, Slovakia, Slovenia and Croatia). There is not much relevant literature available for these specific countries, but some essential works are listed regardless. Brief essential information on open access for all these countries can be found on the OpenAIRE project website (OpenAIRE, 2012). Furthermore, a study was published on the global development of the open access issues in Eastern Europe (Kuchma, 2010). A complex treatment of open access issues can be found especially for Croatia (Hebrank Grgic and Barbaric, 2011; Hebrank Grgic, 2009; Stojanovski et al., 2009), but also for Poland (Swan, 2010a; Swieckovska, 2011). There was also some material published about one of the core projects towards open access in Slovenia (Biggins, 2008). Specialized information about the issue in Hungary and the Slovak Republic are published exclusively in their respective national languages and it is not entirely appropriate to be mentioned here. These sources may serve to gain better understanding of the development of open access in the given countries, while the Czech conditions and specifics are detailed below in the article. A more detailed comparison of the specifics of each country in the area of open access could certainly be included in a separate study.

\section{Methodology}

The research is supported by the analysis of data from prestigious databases - Journal Citation Reports, Scopus and DOAJ. Journal Citation Reports was used to evaluate all Czech impacted journals and this results in an analysis of number of paid and open access journals from the Czech Republic. The same approach was used with the Scopus database. Although 
the data on the Scopus documentation portal do contain the information whether the included journals are registered in DOAJ, it is not completely relevant because not all freely accessible journals are listed in DOAJ. Therefore a more detailed analysis was made, which clearly divides the journals from Scopus into paid and freely accessible journals. The DOAJ database then served as a resource for a more detailed specification of registered Czech OA journals and at the same time as a basis for comapring the number of registered Czech OA journals with other Central European countries. These countries (Poland, Hungary, Slovakia, Slovenia and Croatia) were selected purposefully, because they have gone through a similar historical development like the Czech Republic and after the fall of communism they were on the same starting line in scientific publishing. A comparison with e.g. developed West European countries or USA would not be completely relevant. For repositories, data from ROAR and OpenDOAR was examined. This was again a comparison of the number of repositories with the mentioned Central European countries. Apart from that, the ROAR and OpenDOAR registries served for a detailed analysis of listed Czech repositories concerning their type, used software, number of records etc. The goal of all these analyses is to determine the Czech specifics in the area of open access and evaluating success of Czech Republic in the international context.

\section{The system of science in Czech Republic}

To grasp the situation completely one must first understand how the system of science and research works overall in the Czech Republic. The essential organization for advancement of science in the Czech Republic is the Research, Development and Innovation Council[10] which is the government advisory body. According to its statute, the prime minister is its chairman. Within the scope of this body is for instance forming the national strategy on science and research, defining priorities of applied research, development and innovation, making analyses and presenting opinions to the government in the field of science, research and innovation. The Research, Development and Innovation Council also suggests nominations of members of the board and the chairman of the Technology Agency of the Czech Republic[11] and the Czech Science Foundation[12]. These institutions are the major providers of science and research funding in the Czech Republic. Czech institutions may apply for additional financial support from the funds of the European Union, especially from the operational programs Research and Development for Innovation and Education for Competitiveness.

One of the most important tasks of the Research, Development and Innovation Council is formulation of rules for evaluation and funding of science and research organizations in the Czech Republic. This methodology is then not only used to evaluate quality of publications of individual institutions but that is also authoritative for subsequent funding of these institutions from the national budget. Science and research organizations submit their outputs annually into the RIV (Information Register about R\&D Results)[13] system where they are scored and subsequently financially rewarded. Among significant eligible outputs, there are scientific monographs, conference papers, patents and prominently, scientific articles. These are scored and financially rewarded only if the source journal is either:

a) in Journal Citation Reports; or

b) in Scopus; or

c) in the ERIH registry; or 
d) in the list of peer-reviewed, non-impacted periodicals published in the Czech Republic.

Authors are therefore compelled by the management of their institutions to publish their articles only in these types of journals. The ideal case is impacted journals because they receive the highest score, and in turn, secure the highest financial rewards.

In principle Czech science and research institutions can be classified into several categories. Most prominently, there are various departments of the Academy of Science and universities. There are also so-called public research institutions, which are not established by the Academy of Science. Research in the field of medicine is also done in hospitals, especially university (faculty) hospitals. For illustration purposes, Table 1 contains the five most productive Czech institutions in the Web of Science and Scopus databases in 2012.

\begin{tabular}{|l|c|c|}
\hline Institution & Number of Records (WoS) & Number of Records (Scopus) \\
\hline $\begin{array}{l}\text { The Academy of } \\
\text { Sciences of the Czech } \\
\text { Republic }\end{array}$ & 2886 & 1907 \\
\hline $\begin{array}{l}\text { Charles University in } \\
\text { Prague }\end{array}$ & 2636 & 850 \\
\hline Masaryk University & 833 & 624 \\
\hline $\begin{array}{l}\text { Palacký University } \\
\text { Olomouc Technical }\end{array}$ & 660 & 1040 \\
\hline $\begin{array}{l}\text { Czech } \\
\text { University in Prague }\end{array}$ & 617 & \\
\hline
\end{tabular}

Table 1 - Top numbers of records in the Web of Science and Scopus databases as of November 9, 2012 among Czech scientific institutions. Source: Web of Science, Scopus

\section{Organizations supporting open access in the Czech Republic}

Unfortunately, we have to begin by stating that the official national policy in the field of science and research completely ignores open access. The key document The National Research, Development and Innovation Policy of the Czech Republic in 2009 - 2015 does not mention open access even once. But that does not mean that there is no development in this area in the Czech Republic. Some individual institutions have adopted the principles and policy of open access, but not many of them. Only 5 institutions have adopted open access by signing the Berlin Declaration:

- The Academy of Science of the Czech Republic

- Masaryk University

- Association of Libraries of Czech Universities

- Czech Science Foundation

- MAGNANIMITAS

While the Academy of Science has been very active in the open access field in the long term and it clearly defined its publishing policy as early as 2010 (ASCR 2010), universities do not heed this issue appropriately, an exception being Masaryk University which supports the ideas of open access, but tangible activities to support it are still to be introduced.

At the rest of the universities, the initiative for open access support comes mostly from their respective libraries. For instance, there are significant efforts of the library of VŠB-Technical University of Ostrava which represents Czech Republic in the OpenAIRE international project. The activities of university librarians were crowned in spring 2012 when the 
Association of Libraries of Czech Universities[14] which is made up of 23 Czech universities, officially signed the Berlin Declaration. Its members have thereby undertaken maximum support of open access at their respective institutions. Nowadays many university libraries join the Open Access Week event, which traditionally takes place annually at the end of October. There is also the newly founded openaccess.cz[15] platform, and other events for popularization of this matter can be expected. As a purely formal step, the Czech Science Foundation signed the Berlin Declaration, too. They have not yet added the requirement to publish in open access mode into their rules for receivers of funding.

The situation in other countries listed in this article must also be mentioned. In Slovenia, the open access policy is a part of the government's strategy for science and research support. Croatia is currently working on such document. In Poland and Hungary, open access publishing is supported by important institutions financing science and research. Only in Slovakia (and the Czech Republic) is this issue completely ignored on the national level.

\section{The Golden Road}

Czech authors publishing articles in freely available journals are a relatively common occurrence; however, that is not due to publishing policies of individual scientific institutions or high information literacy of the authors. This issue must be divided into two basic scenarios. The first one is publishing in Czech scientific journals. There is an unusually high number of open access journals among them. To explain this phenomenon, it is necessary to understand the situation of Czech publishers. There is no big commercial publisher. Thus, the majority of journals are being created directly by the main representatives of science and research - universities and departments of Academy of Science. These subjects are not normally interested in profit from publishing, so they make the published articles freely available. In spite of that, publishing of scientific journals can pay off richly for these universities. If the journal has a high enough quality and is on the aforementioned list of scored journals according to the methodology of Research, Development and Innovation Council, the articles contained therein are financially rewarded. That means of course that there is certain space available for authors from the home institution which subsequently gets the financial benefits (after submitting the data into RIV). So what is the share of Czech open access journals? For illustration purposes, here are the analyses of Journal Citation Reports[16], Scopus[17] and Directory of Open Access Journals (DOAJ)[18].

\begin{tabular}{|l|c|c|}
\hline Database & Journals Total & Open Access Journals \\
\hline $\begin{array}{l}\text { Journal Citation Reports - } \\
\text { Science Edition 2011 }\end{array}$ & 33 & 20 \\
\hline $\begin{array}{l}\text { Journal Citation Reports - } \\
\text { Social Science Edition }\end{array}$ & 10 & 4 \\
2011 & & \\
\hline
\end{tabular}

Table 2 - Total number of Czech journals in the JCR database and the number of journals accessible in open access mode. Source: JCR

As Table 2 shows, over 50\% of Czech impacted journals are open access journals. Only titles which are freely available immediately after publishing are counted among those titles. Some other journals offer the authors to publish their article in open access mode in return for a fee or they publish full texts freely after a certain time period following publication (so-called embargo). However these journals are not listed as open access in our table.

The Scopus database contains more Czech journals. Currently there are 122 titles and the documentation of Scopus claims, that 17 of them are also in DOAJ. But the real count is different, because not every freely available magazine is registered in DOAJ. The analysis of 
Czech titles showed the following numbers: out of 122 titles in Scopus, 52 titles are freely available.

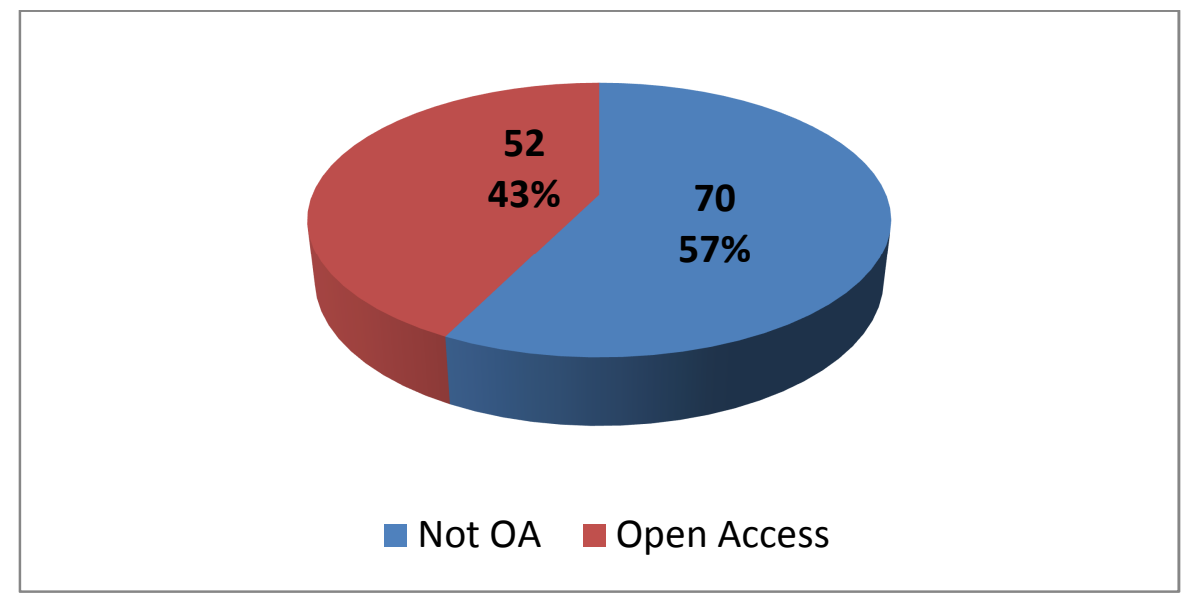

Figure 1 - Division of Czech journals indexed in the Scopus database

The DOAJ database can then be used as an indicator for international comparison. Currently, there are 66 Czech journals registered in this service, which makes the Czech Republic 29th in ranking of countries. The number of Czech journals in DOAJ is ever growing.

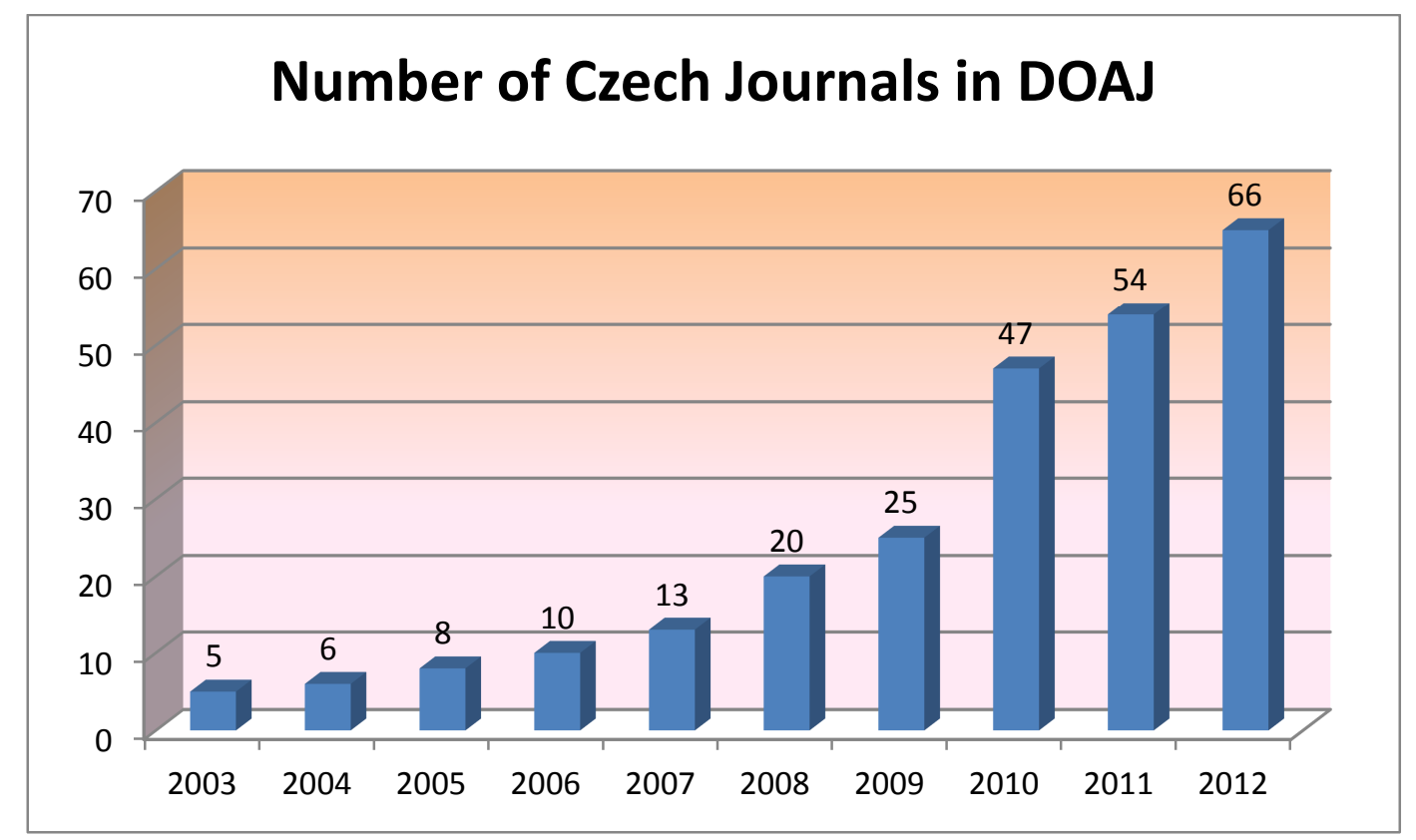

Figure 2 - Number of Czech journals registered in DOAJ as of November 9, 2012. Source: DOAJ

A significant increase in registered titles in recent years indicates that the open access issue has started moving into the foreground of interests of Czech institutions only recently. But the Czech Republic does not lag in comparison to their Central European competitors in the number of available journals, as Table 3 illustrates. 


\begin{tabular}{|l|c|c|}
\hline Country & Number of Journals & Ranking in DOAJ \\
\hline Poland & 138 & 16. \\
\hline Croatia & 87 & 24. \\
\hline Czech & 66 & 29. \\
Republic & & 40. \\
\hline Slovenia & 36 & 45. \\
\hline Slovakia & 31 & 49. \\
\hline Hungary & 24 & . \\
\hline
\end{tabular}

Table 3 - Comparison of number of journals registered in DOAJ in selected countries as of November 9, 2012. Source:

DOAJ

Detailed specifications of registered journals are needed for better illustration. An interesting finding is that the topical breakdown of Czech journals in DOAJ is very wide. At least one Czech journal is represented in 40 topical categories. Most Czech journals are in the category of Political Sciences (6), five titles are classified into each of the categories Economics and "Business and Management". Four magazines are the area of Medicine. Regarding division by language, only three magazines contain articles exclusively in English. On the other hand, the vast majority of journals, namely 39 titles are published only in Czech. The rest of the journals allow authors to publish articles in several languages (in addition to Czech and English also in German and Slovak). Fees are a very important issue. According to data from DOAJ more than two-thirds of Czech journals do not ask fees from authors for publishing their articles.

A whole new chapter is publishing articles of Czech authors in foreign journals. Czech scientific journals in most cases do not achieve the necessary impact (and are the least valued according to the Czech evaluation methodology) and authors usually consider them a stepping stone for their further professional development and subsequent publication in foreign journals. Understandably, the goal of the best Czech scientists is to publish in prestigious impacted journals and the issue of availability of these articles is being pushed into background by these authors. The culprit here is especially low awareness of the open access issue in individual institutions and pressure on the authors. They are often put into a situation, where they are asked to produce a high number of outputs in prestigious journals and there is no time or energy left for the author to solve the issue of full text accessibility (publishing in an open access journal or an open access repository).

That is because only a small number of subjects deal with the issue of open access at the institutional level. The activities here are currently developed only by the Masaryk University and by the Czech Academy of Science which is undoubtedly the leader in open access publishing. Apart from having a clear definition of its publishing policy, it has a fund for support of the golden road open access. This fund gets 1 million Czech crowns (approx. 40 thousand Euros) annually. Authors may then ask for a contribution to cover the costs of publishing their article in open access mode in hybrid journals (BUREŠOVÁ, 2012). Other Czech institutions do not usually support these activities, especially for economic reasons and also because the issue of open access simply does not get the appropriate attention.

\section{The Green Road}

The second approach to support free distribution of scientific results is archiving them and making them accessible via open repositories. These repositories may be of different natures. If we accept the classification to subject-based repositories and institutional repositories (McCulloch, 2006; Hubbart, 2003) we must conclude that there is but one repository of the former type. The explanation is simple - the Czech Republic is no world leader in terms of 
science output or in presence of prestigious scientific institutions, therefore there are no subject-based repositories, either. The Czech Republic is no leader in institutional repositories, either. Although this issue has been often debated recently and some institutions are hard at work developing their repositories (e.g. Masaryk University), the number of working repositories is still very low. The blame here must be put especially on the passiveness of management of universities and other scientific institutions. The issue at hand has not been discussed at all for a long time and all initiative came from the bottom up; from academic libraries.

The long-term lack of institutional repositories forced some prolific authors to archive their articles in large subject-based repositories. Contributions from Czech authors can be found in established services like arXiv[19], RePec[20] or E-lis[21]. For example, the RePEc service registers 43 Czech institutions and several hundred authors. There is no need to remind that these are usually organizations that do not have an institutional repository. The significantly smaller E-Lis database contains 41 articles by Czech authors.

Much larger attention in recent years was given to accessioning of ETDs. Much of the work here was done by the committee established by the Association of Libraries of Czech Universities. The committee produced several standards and recommendations and nowadays we can conclude that almost all Czech universities have their theses available in their digital repositories. There is also the central theses.cz service which is a kind of central catalogue of Czech theses. At this point it is appropriate to mention the development of ETD repositories. The key moment here was the change in the Higher Education Act in 2005, which imposed universities to publish the theses of their graduates. Almost all major universities responded to this legislative change and quickly began to build repositories of ETDs. This leads us to the conclusion that there are no technical barriers to creating institutional repositories, all barriers are rather organizational or stemming from inactivity of state authorities.

That is because the situation in the repositories of scientific research outputs of universities is vastly different. As neither the legislation in force, nor the current system of evaluation of research activities does not recognize concepts like open access or institutional repository, the activities of universities in this area are very limited. Building them requires cooperation of individual authors and support from institutional management, which is often lacking. There are currently only three fully fledged institutional repositories featuring the complete publication output of their institutions. The established repositories of VŠB-Technical University of Ostrava[22] and University of Pardubice[23] were joined in 2011 by the technically very advanced repository of publications of Tomas Bata University in Zlín[24]. It is necessary to say that none of the three archives work solely in open access mode. There are materials in them which are only accessible internally for faculty and students of their respective universities. Among the reasons is a certain vigilance of the authors who do not want to publish their works completely freely, but also a low awareness about the options of archiving and accessioning via institutional repositories. All services listed here are based on the DSpace platform. This fact is not surprising because in the Czech Republic there is a very active DSpace.cz[25] working group contributing to popularization and adoption of DSpace in the Czech academic environment. DSpace also has other instances in the Czech Republic, especially repositories of ETDs but also the Czech Digital Mathematics Library[26] which is a digital library of Czech mathematical journals.

The ROAR registry[27] currently lists 6 repositories from the Czech Republic, two of them being institutional repositories. Then there are two services distributing electronic journals. 
The first one being the aforementioned DML, the second one dKNAV[28] which is accessioning electronic journals published by the Academy of Science of the Czech Republic. This service is special in being built on the EPrints 3 platform. The next service in ROAR is the National Repository of Grey Literature[29] which is a central service for collecting, archiving and accessioning of grey literature in the Czech Republic (however, so far it has not built the necessary network of partner institutions for delivery of materials). The last repository is Inforum 2006[30]. Rather than a typical repository, this is a collection of the traditional international conference about information resources. The competing registry OpenDOAR[31] contains the very same items (with the exception of kNAV missing from OpenDOAR; and missing in ROAR is University of West Bohemia Digital Library[32] with only 53 items so far). As shown by Table 4, which compares the number of repositories registered in Central European countries, the Czech Republic is approximately average, but the number of open repositories in Hungary and especially in Poland is many times higher.

\begin{tabular}{|l|c|c|}
\hline Country & Records in ROAR & Records in OpenDOAR \\
\hline Poland & 77 & 75 \\
\hline Hungary & 14 & 12 \\
\hline Czech & 6 & 7 \\
Republic & 4 & 6 \\
\hline Croatia & 4 & 5 \\
\hline Slovenia & 0 & 0 \\
\hline Slovakia & & \\
\hline
\end{tabular}

Table 4 - Comparison of number of repositories registered in the ROAR and OpenDOAR services in selected countries as of November 9, 2012. Source: ROAR, OpenDOAR

In DRIVER, the most important European initiative for support of open archives, which is also the union catalogue for searching repositories, the Czech Republic has three representatives (repositories of University of Pardubice, VŠB-Technical University of Ostrava and kNAV). OAIster[33] is another significant service for searching in open repositories. This system is currently run by the OCLC organization and has over 1100 contributors. Czech repositories are again represented only by repositories of University of Pardubice and VŠBTechnical University of Ostrava.

\begin{tabular}{|l|c|c|c|c|c|c|}
\hline \multicolumn{1}{|c|}{ Repository Name } & OpenDoar & ROAR & Software & Subject & Type & Number of Records \\
\hline Czech Digital Mathematics Library & YES & YES & DSpace & Mathematics & Research Cross-Institutional & 32698 \\
\hline National Repository of Grey Literature & YES & YES & Invenio & Multidisciplinary & Other \\
\hline Digital Library of the University of Pardubice & YES & YES & DSpace & Multidisciplinary & Institutional & 231172 \\
\hline Dspace of VSB Technical University of Ostrava & YES & YES & DSpace & Multidisciplinary & Institutional & Institutional \\
\hline University of West Bohemia Digital Library & YES & NO & DSpace & Multidisciplinary & 205523 \\
\hline Inforum Conference Proceedings & YES & NO & HTML & Library and Information Science & Conference Proceedings & Unknown \\
\hline Inforum 2006 & YES & YES & HTML & Library and Information Science & Conference Proceedings & 106 \\
\hline Dknav & NO & YES & EPrints & Multidisciplinary & Other \\
\hline
\end{tabular}

Table 5 - Detailed specification of Czech repositories as of November 9, 2012. Source: ROAR, OpenDOAR

\section{Conclusion}

It can be concluded from the aforementioned facts, that open access is not yet very well established in the Czech environment. There is no pressure from the government bodies and funding providers to support free accessioning of science and research outputs. As a result, 
science and research organizations do not pay appropriate attention to this issue. In the long term, this issue of open access awareness has been undervalued especially among the faculty of universities who are the most prolific authors of articles. Moreover, as a result of the system of science and research funding in the Czech Republic, they are forced to produce a high number of outputs and they do not pay attention to how they are accessioned. There are many freely available journals published in the Czech Republic, but this is because their publishers are mostly universities and departments of the Academy of Science. There are no larger scientific publishers in the Czech Republic. The top authors then, as a matter of course, publish in prestigious foreign journals and do not concern themselves too much with the issue of making their articles in open access mode. Institutional repositories are not very widespread in the Czech environment. The problem must be solved in management of science and research institutions because the significant commonness of ETD repositories indicates that organizations are technically well prepared to create and run institutional repositories.

In conclusion, it should be noted that the open access issue is getting more attention in the Czech Republic after all and therefore not only the creation of new repositories can be expected, but especially that the authors themselves will care much more about making their publications accessible in open access mode. The whole issue also has a strategic nature. Czech science is largely undermined by the fact that state authorities have so far completely ignored the issue of open access. The change in the Higher Education Act in 2005 launched a massive increase in number of EDT repositories. Should the government proceed in a similar manner in the methodology of science and research evaluation and took into account open access and institutional repositories, it would likely lead to not only an increase in number of repositories, but it also would define a clear policy of publication for each scientific institution, having a positive impact on the overall production of the Czech Republic scientific outputs. An entirely new methodology for evaluating results of science and research is being planned for 2014. It is not yet known exactly how it will look, but in any case it will have a big impact on the whole scope of Czech science. Whether it changes the view of Czech scientists on open access publication and their publishing behavior in some way will surely be a topic of many future studies. 


\section{Notes}

1 See: http://oa.mpg.de/lang/en-uk/berlin-prozess/berliner-erklarung/

2 See: http://www.earlham.edu/ peters/fos/bethesda.htm

3 See: http://www.soros.org/openaccess/read.shtml

4 See: http://www.driver-repository.eu/

5 See: http://www.openaire.eu

6 See: http://www.peerproject.eu/

7 See: http://www.coar-repositories.org/

8 See: http://www.openarchives.org/

9 See: http://www.jisc.ac.uk/

10 See: http://www.vyzkum.cz/Default.aspx?lang=en

11 See: http://www.tacr.cz/en/

12 See: http://www.gacr.cz/

13 See: http://www.vyzkum.cz/FrontClanek.aspx?idsekce=986

14 See: http://www.akvs.cz/

15 See: http://www.openaccess.cz/cs/openaccess/

16 See: http://thomsonreuters.com/products_services/science/science_products/az/journal_citation_reports/

17 See: http://www.scopus.com/home.url

18 See: http://www.doaj.org/

19 See: http://arxiv.org/

20 See: http://repec.org/

21 See: http://eprints.rclis.org/

22 See: http://dspace.vsb.cz/

23 See: http://dspace.upce.cz/

24 See: http://publikace.k.utb.cz/

25 See: http://dspace.cz/

26 See: http://dml.cz/

27 See: http://roar.eprints.org/

28 See: http://dlib.lib.cas.cz/

29 See: http://www.nusl.cz/

30 See: http://sbornik.inforum.cz/cs/

31 See: http://www.opendoar.org/

32 See: https://otik.uk.zcu.cz/

33 See: http://www.oclc.org/oaister/ 


\section{References}

Armbruster, B. and Romary, L. (2009), "Comparing repository types: Challenges and barriers for subject-based repositories, research repositories, national repository systems and institutional repositories in serving scholarly communication", available at: http://arxiv.org/ftp/arxiv/papers/1003/1003.4187.pdf (accessed August 23, 2012).

ASCR (2010), "Open Access Policy at the Academy of Sciences of the Czech Republic", available at: http://www.cas.cz/o_avcr/zakladni_informace/dokumenty/politika-otevrenehopristupu.html (accessed August 20, 2012).

Biggins, M. (2008) “The Digital Library of Slovenia (dLib.si)”, Slavic \& East European Information Resources, Vol. 9, Iss: 3, pp. $294-298$

Bird, C. (2010), "Continued adventures in open access: 2009 perspective", Learned Publishing, Vol. 23 No. 2, pp. 107 - 116.

Burešová, I. (2012), "Jak otevřít přístup k open access", paper presented at Inforum 2012, 22 - 24 May, Prague, Czech republic, available at:

http://www.inforum.cz/pdf/2012/buresova-iva-1.pdf (accessed August 27, 2012).

Harnad, S., Brody, T., Vallières, F., Carr, L., Hitchcock, S., Gingras, Y., Oppenheim, C., Stamerjohanns, H., Hilf, E.R. (2004), "The green and the gold roads to Open Access", Nature, available at: www.nature.com/nature/focus/accessdebate/21.html (accessed August 23, 2012).

Harnad, S., Brody, T., Vallieres, F., Carr, L., Hitchcock, S., Gingras, Y., Oppenheim, C., Hajjem, C., Hilf, E. (2008), "The access/impact problem and the green and gold roads to open access: an update", Serials Review, Vol. 34 No.1, pp.36-40.

Hebrang Grgic, I. (2009) “Open Access in Croatia: a study of authors'perceptions”, Infuture 2009: digital resources and knowledge sharing, Zagreb, Croatia, pp. 169-176

Hebrang Grgic, I., Barbaric, A. (2011) "The future of open access in Croatia: a survey of academic and research libraries", Library Review, Vol. 60 Iss: 2, pp. 155 - 160

Hubbart, B. (2003), "SHERPA and institutional repositories", Serials, Vol. 16 No. 3, pp. 243 $-247$.

McCulloch, E. (2006), "Taking stock of open access: progress and issues", Library Review, Vol. 55 Iss: 6, pp. $337-343$.

Kuchma, I. (2010), "Open access in Eastern Europe: Removing barriers to knowledge sharing", available at: http://cvtisr.sk/itlib/itlib112/kuchma_orig.doc (accessed November 7, 2012).

OpenAIRE (2012), "Overview of Open Access in the EU member states", available at: http://www.openaire.eu/en/open-access/country-information (accessed November 7, 2012). 
Stojanovski, J., Petrak, J., Macan, B. (2009) "The Croatian national open access journal platform", Learned Publishing, Vol. 22, Iss: 4, pp. $263-273$

Suber, P. (2009), "Timeline of the Open Access Movement", available at: www.earlham.edu/ peters/fos/timeline.htm (accessed August 20, 2012).

Swan, A. (2010), "The open access citation advantage: studies and results to date", Technical Report, School of Electronics \& Computer Science, University of Southampton, Southampton, available at:

http://eprints.ecs.soton.ac.uk/18516/2/Citation_advantage_paper.pdf (accessed August 27, 2012).

Swan, A. (2010a) “Open Access - What's in it for Poland?", paper presented at Second International Conference on Open Access in Poland, 14 - 15 January 2010, Torun, Poland, available at: http://eprints.soton.ac.uk/268399/ (accessed November 7, 2012).

Swieckowska, T. (2011) “Open Access in Poland", paper presented at PKP Scholarly Publishing Conference 2011, 26. - 28. September, Berlin, Germany, available at: http://pkp.sfu.ca/ocs/pkp/index.php/pkp2011/pkp2011/paper/view/308 (accessed November 9, 2012).

Waltham, J. (2005), "JISC: Learned society open access business models", available at: http://www.marywaltham.com/JISCReport.pdf (accessed August 27, 2012). 